\title{
Patients' Satisfaction about Health Services in Out-patients Clinics of Teaching Hospitals in Erbil city
}

\author{
Ako Ramadan Satar; Daub Health Centre, Kirkuk Directorate of Health, Ministry of Health, Kirkuk, Iraq. \\ Ibrahim Hassan Mustafa; Department of Nursing, College of Nursing, Hawler Medical University, Erbil, Iraq. \\ (Correspondence: ako.ramadan@yahoo.com )
}

\begin{abstract}
Background and objectives: Outpatients' satisfaction is important aspect to evaluation levels of quality and quantity services provided in outpatients departments. The study aimed to assess patients' satisfaction toward health care provided in out-patients clinics of Rizgary and Hawler Teaching Hospitals and find out the factors that are associated with levels of satisfaction.

Methods: A cross-sectional study was conducted in Hawler and Rizgary Teaching Hospitals in Erbil city. The study started from April 1st, 2017 to July 1st, 2017. A convenience method of sampling was used to recruit 500 participants who attended in Out-patients Clinics 238 (47.6\%) from Rizgary Hospital, and 262 (52.4\%) from Hawler Hospital. The questionnaire format was designed by researches for data collection. The questionnaire consisted of two parts: part one socio-demographic and hospitalization data and part two included 59 questions about health care services. Five points Likert scale was used to assess patients' satisfaction. The Statistical Package for the Social Sciences, version 22 was used data enter and analysis. A chi-square test of association was used to compare proportion.

Results: The study found $27.8 \%$ of patients were satisfied, with respect to all health services (including physicians, nurses, pharmacies, and laboratories) and in health aspects (including communication, maintain for privacy of patients and respect them, counseling and advising roles, and time spend with patients). There was an association between patients' satisfaction and age categories, levels of income, and the number of visits to outpatient departments.

Conclusions: The majorities of outpatients have no idea regarding satisfaction or not satisfied with health services in outpatients departments of major hospitals in Erbil city. There were significant association between the level of satisfaction with age, level of income and hospital.
\end{abstract}

Keywords: Patients' satisfaction, Outpatients departments.

Received: 23/9/2018

Accepted: 15/1/2019

Published: 30/5/2019

\section{INTRODUCTION}

Clients satisfaction refers to the levels of satisfaction that the clients experience having used a medical service in all levels and all domains. Satisfaction is the reflects the gap between the target or desired services and experiences of services provided by health care professionals, from the clients' view [1,2]. Out-Patients Department (OPD) is a department that provides the main linkage of the hospital with the public, its primary objective to provide medical services for the clients in minimal costs, and its scope of services are different from 
area to area, mostly OPD's the services are curative (including diagnosis and treatment), follow up of chronic diseases and referring, in addition rehabilitation, and some time immunizing [3]. Many studies indicated that increased level of quality of health services has relationship with increased level of clients' satisfaction [4]. Studies aimed to find methods to increase clients' satisfaction the results indicated that the hospitals' administrations should create new methods to decrease waiting time in clinics, improve good dialogues skills between healthcare professionals and patients, and maintain privacy of patients. In addition, tudies recommended it's necessary to do training courses for physicians and other health care professionals to improve their abilities and skills to counseling and guiding the patients $[5,6]$. A study by Nabbuye-Sekandl and his collogues carried in Mulago Hospital, Uganda in year 2011. Results indicated that health services provided in hospital should devise innovative ways to reach high satisfaction scores for outpatients clinic care. Adequate facilities should provide for patients and services should be more patients-centered in outpatients clinics to achieve all clients' needs [7]. For the purpose of assessing levels of clients' satisfaction, hospitals' administrators periodically need to gather and analysis related data to identify quality of healthcare services in actually and using the results for improving the quality of healthcare service for better levels [8-10]. Health services are different from country to country but in well-functioning health systems the health services should have number of characteristics including comprehensive, accessibility, caregiver, continuity, quality, person-centeredness, coordination and accountable and efficiency [11] . Few studies concerned on outpatient's satisfaction toward health services provided in public hospital in Erbil city.
This study aimed to assess patients' satisfaction with health care services provided in out-patients clinics of Rizgary and Hawler Teaching Hospitals and find out the factors that are associated with levels of satisfaction .

\section{METHODS}

A cross-sectional study was conducted in Out-patients Departments of Hawler and Rizgary Teaching Hospitals in Erbil city. During April 1st, 2017 to July 1st, 2017.

A convenience method of sampling was used to recruit 500 participants who attended in out-patients clinics 238 (47.6\%) from Rizgary Hospital, and 262 (52.4\%) from Hawler Hospital. The sample size was determined by Yamance statistical formula $(n=N / 1+N(e) 2)$ [12], after estimating the rate of patients visited in the both OPDs in the month from the medical record. (The small $n$ letter in formula indicated to sample size, the Capital $\mathrm{N}$ letter indicated to population size, and e small letter indicated to level of precision of sampling error which equals to 0.05). By process of entering the known data in formula and as $(3858) / 1+(3858) *(0.05) 2=362$ sample size, researchers selected 500 patients as a study sample to reach more representative sample size and for purpose strengthening study. Patients' age $\geq 18$ years, both genders, have $\geq 2$ times visiting during one year were included. Patients with mental or psychological problems were excluded. Data was gathered by the self-report method by using the questionnaire format that was designed by researchers. The validity of the questionnaire was assessed by fifteen experts from different medical and nursing fields. The questionnaire consists of two parts; part one related to socio-demographic characteristics of patients and hospitalization data (such as age, gender, marital status, levels of family income in the month, the 
number of visiting outpatients' clinics, and hospitals). Part two includes a number of questions about health care services. A five-point Likert scale was used to assess patients' satisfaction, were score five indicated the highest level of satisfaction and score one indicated the lowest level of satisfaction. Patients were asked 59 questions to assess their satisfaction with health care services. The equation accrued by subtracting lower score (59) from upper score (295) then the result divided by three. Dissatisfied (59-137) Neutral (138216) and Satisfied (217-295). To identify out-patients satisfaction about health professionals including physicians, nurses, pharmacies, laboratories and facilities (included number and type of seats, adequately car parking, cleanness status, directional follow inside clinics, heating, cooling, lighting and ventilation system) and to identify patients satisfaction for the aspects of the healthcare services that provided by the healthcare professionals (including communication skills, respects and maintain the privacy of patients, advises and counseling role for patients, and amount of time spent with patients) each one of these items in separates scores. The researchers calculated all scores related to each one of them, then presented it into three levels: dissatisfied (for the low score), neutral (for the medium score) and satisfied (for the high score). The research was approved by the Ethical Committee of the College of Nursing, Hawler Medical University and permission from General Directorate of Health in Erbil city. The Statistical Package for the Social Sciences (SPSS, version 22) was used data enter and analysis. The descriptive statistical analysis which involved frequency, percentage, mean and standard division were used. Chi -square test of association was used to compare proportion. A $\mathrm{P}$ - the value of $\leq$ 0.05 was considered as statically significant.

\section{RESULTS}

The mean of patients' satisfaction score ( $\mathrm{M} \pm \mathrm{SD}$ ) was $180.7 \pm 29.4$ (Table 1 ). The proportion of male and female were rough to equal. The highest percentage of the sample was $42.8 \%$ among age category 19 to 29 years, followed by $38.6 \%$ was age category 30 to 40 years. results show that more than half $(51.2 \%)$ of the study sample has enough income for daily life, followed by $46.2 \%$ of the sample mentioned there income level is not enough for daily life. results show that $58 \%$ of the sample has 2-3 times visiting outpatients' clinics during one year (Table 2). Results showed that the highest scores more than half in majority in all out-patients departments were recorded in neutral (among them the highest score $63.4 \%$ was recorded in facilities services, and lowest score 46.8 was recorded in laboratory services), only $16.0 \%$ of the sample was high satisfied toward nursing services, and $31.6 \%$ of the sample was dissatisfied toward laboratory services (Table 3). Results showed the satisfaction of out-patients toward health care aspects were scored in majorly neutral for all aspects more than half of the sample $54.6 \%$ and $53.8 \%$ respectively were scored neutral satisfaction for the time which spends with patients and maintains patient privacy and respects respectively. Regarding communication highest score $45.4 \%$ was scored in neutral satisfied the rest was rough to equal distribute between satisfied and dissatisfied. Regarding health professionals' advice and counseling more than one third $(38 \%)$ of the patients were neutral, and more than a quarter of them (25.8\%) were dissatisfied (Table 4).

Results show more than half 257 (51.4\%) of the sample was neutral satisfied about health services, and 139 (27.8\%) was satisfied, the rest 104 (20.8\%) was dissatisfied. Results also show that there was no 
differences between male and female regarding levels of satisfaction (dissatisfied, neutral, and satisfied) (P. value $=0.144)$. Results show more than half $(54.8 \%)$ of dissatisfied were patients in the age group 2029 , and $38.1 \%$ of the satisfied were patients in the age group 40 and more. Highly significant statistically differences ( $P$. value $<0.001$ ). Results also show that only 13 (2.6\%) of the whole sample has exceeded enough income for daily life among them $0.0 \%$ were recorded in dissatisfied, the others were distributed between neutral and satisfied respectively. Patients who have enough income for daily life harvested $70.5 \%$ in the satisfied group. Highly significant statistically differences ( $p$. value $<0.001$ ). Regarding differences of levels of satisfaction between the clients of both hospitals (Rizgary and Hawler) results show $75.5 \%$ of satisfied patients were clients of Hawler Hospital, against only $24.5 \%$ of them were clients of Rizgary Hospital Highly significant statistically differences ( $p$. value $<0.001$ ) (Table 5).

Table1: Describe satisfaction status of study sample

\begin{tabular}{ccccc}
\hline Mean & Minimum & Maximum & Range & Stander Deviation \\
\hline 180.7 & 112.0 & 240.0 & 128.0 & 29.4 \\
\hline
\end{tabular}

Table2: Socio-demographic characteristics of the study sample

\begin{tabular}{|c|c|c|}
\hline Variables & No. & $\%$ \\
\hline \multicolumn{3}{|l|}{ Sex } \\
\hline Male & 249 & 49.8 \\
\hline Female & 251 & 50.2 \\
\hline \multicolumn{3}{|l|}{ Age } \\
\hline $19-29$ & 214 & 42.8 \\
\hline $30-40$ & 193 & 38.6 \\
\hline 41-51 & 93 & 18.6 \\
\hline \multicolumn{3}{|l|}{ Levels of income } \\
\hline Not enough for daily life & 231 & 46.2 \\
\hline Enough for daily life & 256 & 51.2 \\
\hline Exceeds enough for daily life & 13 & 2.6 \\
\hline \multicolumn{3}{|c|}{ Number of visiting outpatients clinic } \\
\hline $2-3$ visits & 290 & 58.0 \\
\hline 4-5 visits & 210 & 42.0 \\
\hline Total & 500 & 100 \\
\hline
\end{tabular}

Table 3: Patients' satisfaction toward health services

\begin{tabular}{lcccc}
\hline & \multicolumn{3}{c}{ Satisfaction levels } & \multirow{2}{*}{ Total (\%) } \\
\cline { 2 - 4 } Health care aspects & Dissatisfied & Neutral & Satisfied & \\
\hline Physicians & No. (\%) & No. (\%) & No. (\%) & \\
Nursing & $135(27.0)$ & $263(52.6)$ & $102(20.4)$ & $500(100)$ \\
Pharmacy & $136(27.2)$ & $284(56.8)$ & $80(16.0)$ & $500(100)$ \\
Laboratory & $41(8.2)$ & $278(55.6)$ & $181(36.2)$ & $500(100)$ \\
Facilities & $158(31.6)$ & $234(46.8)$ & $108(21.6)$ & $500(100)$ \\
\hline \hline
\end{tabular}


Table 4: Satisfaction level of sample according to outpatients' services

\begin{tabular}{lccc}
\hline & \multicolumn{3}{c}{ Satisfaction levels } \\
\cline { 2 - 4 } Health care aspects & Dissatisfied & Neutral & Satisfied \\
& No. (\%) & No. (\%) & No. (\%) \\
\hline Health professionals' communication & $136(27.2)$ & $227(45.4)$ & $137(27.4)$ \\
Patients' privacy maintain and respect & $147(29.4)$ & $269(53.8)$ & $84(16.8)$ \\
Health professional advice and counseling & $129(25.8)$ & $190(38.0)$ & $181(36.2)$ \\
Time spends with patients & $80(16.0)$ & $273(54.6)$ & $147(29.4)$ \\
\hline
\end{tabular}

Table 5: Association between levels of satisfaction and socio-demographic variables

\begin{tabular}{lcccc}
\hline & \multicolumn{3}{c}{ Levels of satisfaction } & \\
\cline { 2 - 4 } Variables & Dissatisfied & Neutral & Satisfied & \\
& $\mathbf{1 0 4 ( 2 0 . 8 )}$ & $\mathbf{2 5 7 ( 5 1 . 4 )}$ & $\mathbf{1 3 9 ( 2 7 . 8 )}$ & P value \\
\hline Sex & No.(\%) & No.(\%) & No.(\%) & \\
Male & $57(54.8)$ & $117(45.5)$ & $75(54.0)$ & \\
$\begin{array}{l}\text { Female } \\
\text { Age categories }\end{array}$ & $47(45.2)$ & $140(54.5)$ & $64(46.0)$ & 0.144 \\
$\mathbf{2 0 - 2 9}$ & $57(54.8)$ & $110(42.8)$ & $47(33.8)$ & \\
$\mathbf{3 0 - 3 9}$ & $44(42.3)$ & $110(42.8)$ & $39(28.1)$ & $\leq 0.001$ \\
$\begin{array}{l}\text { 40+ } \\
\text { Levels of income }\end{array}$ & $3(2.9)$ & $37(14.4)$ & $53(38.1)$ & \\
Not enough for daily life & $46(44.2)$ & $150(58.4)$ & $35(25.2)$ & \\
Enough for daily life & $58(55.8)$ & $100(38.9)$ & $98(70.5)$ & $\leq 0.001$ \\
$\begin{array}{l}\text { Exceeds enough for daily life } \\
\text { Hospitals }\end{array}$ & $0(0.0)$ & $7(2.7)$ & $6(4.3)$ & \\
Rizgary & & & & \\
Hawler & $63(60.6)$ & $141(54.9)$ & $34(24.5)$ & \\
\hline
\end{tabular}

*The satisfied level consisted $27.8 \%$ of whole sample

\section{DISCUSSION}

The results of this study showed that the average of patients' satisfaction has stayed in 180.7 which is in the second the highest half of the total score (Table 1). Present study show the highest scores in all type of health services were harvested in the neutral, very limited percentage of sample was dissatisfied toward pharmacy services and less than twenty percentage of sample was satisfied toward nursing care (Table 3).
Results of a study carried in Malaysia by Abd Munaf indicated that the overall health satisfaction was high in outpatients of public and private hospitals. The study also finds there was a relationship between satisfaction of patients and waiting time in the outpatient's clinic [16]. Study of Amini and Amiri indicated the most of the patients scored satisfaction with health services; the highest score was recorded for physicians, while the lowest score went 
to time waiting. The inconsistencies among studies maybe related to differences between facilities, and services of hospitals [6].Table 4 in the present study also shows that the highest scores of health professionals about services aspects were distributed majority (more than half and sometimes near to half) for neutral in most behavioral activities which involved times dedicated with patients, maintains privacy of patients and respect them, and communication skills of health professionals with the patients. The results of Table 4 verify the results of table 3in the present study about most of the scores were went to neutral. These results are predictable because the services are available in outpatients clinics but it's not enough in quality and quantity, and our patients have courtesies in there speaking when they evaluate services. In addition patients in Erbil want the service in out-patients whatever type with regardless of its quality. Therefore the results gone to neutral level Studies indicated that training health professional principles of communication skills and counseling is necessary to increase patients' satisfaction [17- 19]. This study shows that $27.8 \%$ of the whole study sample was satisfied toward health services which provided in outpatients clinics of both Rizgary and Hawler Hospitals (Table 5). In a study carried by Asefa and his colleagues in Hawassa University Teaching Hospital, in the year 2014 results indicated that $80.1 \%$ of patients were satisfied towered health services provided in outpatients clinics of the hospital and association between patients' satisfaction and good communication with patients, length of staying in outpatients' clinics to take the healthcare, and available main health services [5].The inconsistencies between the results of the two studies maybe related to differences between qualities of health services in hospitals. The present study shows that there were no differences between male and female regarding satisfaction levels. The Study carried of Nabbuye-Sekandl and his colleagues indicated that there were no significant differences between males and females regarding satisfaction [7]. Regarding age the present study showed satisfaction of outpatients increased in patients age 40 and more the association between age groups and levels of satisfaction were significant. NabbuyeSekandl et al indicates that there were no significant differences between age groups and levels of satisfaction [7]. The present study also shows that there was an association between levels of income and satisfaction of patients towered health services in out-patient clinics. Highest scores of satisfied were recorded with those who have enough income for daily life. The results of a study carried by Net in year 2007 indicated that there was no association between levels of income and levels of out -patients satisfaction [13]. While Pascoe (1983), found that increases income among patients is a factor for decrease satisfaction toward nursing [14]. Al-Tawil et al in the year 2015 indicated that income is subjective and participants could be erroneously classified into different levels of income groups [15]. The association between socio-demographic characteristics of clients and their levels of satisfaction were divers from study to other [4]. Present study found that the satisfaction of outpatients in Hawler Hospital is better than the satisfaction of the outpatients clinic at Rizgary Hospital.

\section{CONCLUSIONS}

Present study concluded that only $27.8 \%$ of the whole sample was satisfied with health services, the majority of scores were recorded neutral satisfaction in all health services. There was a significant association between patients' satisfaction 
and age categories, levels of income, and number of visits to outpatients' clinics, and there was a difference between patients of Rizgary Hospital and Hawler Hospital regarding outpatients' satisfaction.

\section{CONFLICT OF INTEREST}

The authors report no conflict of interests.

\section{REFERENCES}

[1] Prakash B. Patients satisfaction. Journal of Cutaneous and Aesthetic Surgery Sep. 2010; 3(3):151-5. Available from: Doi: 10.4103/0974-2077.74491/.https:// www.researchgate.net/

[2] Aragon SJ, Gesell SB. A patient satisfaction theory and its robustness across gender in emergency departments.American Journal of Medical Science.2003; 18: 229-41.

[3] Singh Bedi S. Impact of Healthcare services on Outpatient Satisfaction in Public and Private Hospitals: A study of Hospitals in Mumbai. [thesis]. Mumbai: D.Y.Patil, University, Navi Mumbai; 2014.

[4] Batbaatar E., Dorjdagva J., Luvsannyam A., Savion MM., Amenta P. Determinants of patient satisfaction: a systematic review. Respect public health Journal. Mar. 2017; 137(2):89-101. Available from: Doi: 10.1177/1757913916634136. http:// www.ncbi.nlm.nih.

[5] Asefa A., Kassa A., Dessalegn M. Patient satisfaction with outpatient health services in Hawassa University Teaching Hospital, Southern Ethiopia. Journal of Public Health Epidemiology. Feb. 2014; 6(2): 101-10. Available from: Doi: 10.5897/JPHE2013.061. www.academicjournals.org

[6] Amerion A., Amini H., Meskarpour M., Ebrahimnia M., Sanaienasab H. Assessment of patient satisfaction and its related factors with outpatient services of Military Hospital clinic in Iran. Wulfenia Journal. Decmb.2014; 19(5):74-83.

[7] Nabbuye- Sekandl J., Makumbl F., Kasangaki A., Kizza I., Tugumisirize J., Nshimye E., et al, Patients satisfaction with services in outpatient clinics at Mulago Hospital, Uganda. International Journal of Quality Health Care. 2011; 23(5):516-23. Available from: doi: 10.1093/intqhc/mzr040.https:// www.ncbi.nlm.nih.gov/pubmed/21775313.
[8] Aldebasi YH, Ahmed MI. Patients' Satisfaction with Medical Services in the Qassim Area. Journal of Clinical and Diagnosis Research. 2011; Res. 5(4):813-817.

[9] Donabedian A. The quality of care: how can it be assessed? Journal of the American Medical Association 1988;260(12):1743-8. Available from Doi: jama.1988.03410120089033.https:// jamanetwork.com/journals/jama/articleabstract/374139.

[10] Cleary PD, McNeil BJ. Patient satisfaction as an indicator of quality care.Journal of Medical care Organization. 1988;25:25-36. Available pubmed/2966123. [Access in May 20, 2018].

[11] WHO. Health service delivery. 2010. Available from:www.who.int/healthinfo/systems/ WHO_MBHSS_2010_section1_web.pdf [Access in March 12, 2018].

[12] Ajays SS., Micah BM. Sampling techniques and determination of sample size in applied statistics research: an overview. International Journal of Economics Commerce and Management, UK; 2014; 2(11)1-22.

[13] Net N. Patients' satisfaction towards health services at the out-patient department clinic of Wangnumyen Community Hospital Sakaeo Province, Sakaeo Province: Mahidol University Thailand. [Thesis]. 2007.

[14] Pascoe GC. Patient satisfaction in primary health care: a literature review and analysis: EvalProg Plan 1983; 6(3-4):185-210. Available from: https://www.ncbi.nlm.nih.gov/ pubmed/10299618. [Access in March 17, 2018].

[15] Al-TawilNG., Mustafa IH., Ismahil ZA. Inpatients satisfaction toward nursing services in medical and surgical wards of Rizgary Teaching Hospital, Erbil, Iraq.Zanco Journal of Medical Science; 2016;20(2):1349-55.

[16] AbdManaf NH, Nooi PS. Patients' satisfaction of services quality in Malaysian Public Hospital. The Asian Journal of Quality. 2016; 10(1): 77-87. Available from: https:// doi.org/10.1108/15982688200700028

[17] Azizam N A, Shamsuddin K. Health care provider- patient communication: a satisfaction study in the outpatients clinic at Hospital Kuala Lumpur. Malays Journal of Medical Science. 2015; 22(3)56-64. Available from: https://www.ncbi.nlm.nih.gov/pmc/articles/ PMC4681722/. [Access in Apr 10, 2018]. 
[18] King MA., Hoppe RB. "Best practice" for patients-centered communication: a Narrative Review. Journal of Graduate Medical Education. Sept. 2013; 5(3):385-93. Available from: doi: 10.4300/JGME-D-1300072.1..https://www.ncbi.nlm.nih.gov/ pubmed/24404300,

[19] Kamhawi S, Underwood C., Murad H., Jaber B. Clients-center counseling improves client satisfaction with family planning visits: evidence from Irbid, Jordan. Global Health Science and Practice Journal. Aug. 2013; 1(2): 180- 92. Available from: http:// www.chwcentral.org/client-centeredcounseling-improves-client-satisfactionfamily-planning-visits-evidence-irbid-jordan. [Access in March 17, 2018]. 